\title{
The effect of premedication with ketamine, alone or with diazepam, on anaesthesia with sevoflurane in parrots (Amazona aestiva)
}

Valéria Veras Paula ${ }^{1 *}$, Denise Aya Otsuki ${ }^{2 \dagger}$, José Otávio Costa Auler Júnior ${ }^{2}$, Talyta Lins Nunes $^{1 \dagger}$, Aline Magalhães Ambrósio ${ }^{3 \dagger}$ and Denise Tabacchi Fantoni ${ }^{3+}$

\begin{abstract}
Background: Premedication is rarely used in avian species. The aim of this study was to evaluate the effect of premedication on the quality of sevoflurane induction and anaesthesia in parrots. We hypothesised that premedication would facilitate handling and decrease the minimum anaesthetic dose (MAD). Thirty-six adult parrots were randomly distributed in three groups: group $S(n=12)$ was premedicated with $\mathrm{NaCl} 0.9 \%$; group $\mathrm{KS}(n=12)$ was premedicated with $10 \mathrm{mg} \cdot \mathrm{kg}^{-1}$ ketamine; and group KDS $(n=12)$ was premedicated with $10 \mathrm{mg} \cdot \mathrm{kg}^{-1} \mathrm{ketamine}^{-1}$ and $0.5 \mathrm{mg} \cdot \mathrm{kg}^{-1}$ diazepam, delivered intramuscularly. After induction using $4.5 \%$ sevoflurane introduced through a facemask, the MAD was determined for each animal. The heart rate (HR), respiratory rate (RR), systolic arterial blood pressure (SAP), and cloacal temperature (CT) were recorded before premedication (T0), 15 minutes after premedication (T1), and after MAD determination (T2). Arterial blood gas analyses were performed at T0 and T2. The quality of anaesthesia was evaluated using subjective scales based on animal behaviour and handling during induction, maintenance, and recovery. Statistical analyses were performed using analysis of variance or Kruskal-Wallis tests followed by Tukey's or Dunn's tests.

Results: The minimal anaesthetic doses obtained were $2.4 \pm 0.37 \%, 1.7 \pm 0.39 \%$, and $1.3 \pm 0.32 \%$ for groups $\mathrm{S}, \mathrm{KS}$, and KDS, respectively. There were no differences in HR, RR, or CT among groups, but SAP was significantly lower in group S. Sedation was observed in both the premedicated S-KS and S-KDS groups. There were no differences in the quality of intubation and recovery from anaesthesia among the three groups, although the induction time was significantly shorter in the pre-medicated groups, and the KS group showed less muscle relaxation.

Conclusions: Ketamine alone or the ketamine/diazepam combination decreased the MAD of sevoflurane in parrots (Amazona aestiva). Ketamine alone or in combination with diazepam promoted a good quality of sedation, which improved handling and reduced the stress of the birds. All protocols provided safe anaesthesia in this avian species.
\end{abstract}

Keywords: Sevoflurane, Ketamine, Diazepam, Parrots

\footnotetext{
*Correspondence: valeria@ufersa.edu.br

${ }^{\dagger}$ Equal contributors

'Department of Animal Science, Universidade Federal Rural do Semi-Árido, Av. Francisco Mota, 572, Bairro Costa e Silva, CEP: 59.625-900, Mossoró, RN, Brazil

Full list of author information is available at the end of the article
} 


\section{Background}

For the last several years, interest in wildlife conservation has promoted an increase in the number of studies concerning the use of anaesthetics in wild birds and domestic fowl [1]. Anaesthesia in birds is challenging, and the literature describes the use of different drugs and dosages for several different species, ranging from canaries to ratites $[2,3]$.

Research based on the study of wild birds is becoming more and more difficult. The Brazilian Institute of the Environment and Renewable Natural Resources (IBAMA) maintains rigid control over activities carried out by researchers, with the aim of preserving the lives of these animals. In contrast, many species are in danger of extinction, which makes studies of these birds essential.

The principal problems with the use of anaesthetics in birds are related to physiological, anatomical, and metabolic differences in birds compared with mammals, the lack of studies in this field, and the large spectrum of species that remain to be found.

As in other species, general anaesthetics in birds may be carried out by the use of injectable agents and inhalation [2].

Pre-anaesthetic medication is rarely indicated for small birds, as these animals can be restrained manually [4]. Nevertheless, small birds are very delicate and extremely sensitive to manual restraint, which makes pre-anaesthetic medication a viable option. Additionally, manual restraint can be extremely stressful to birds, resulting in organic reactions that may interfere with the internal stability of the organism and produce serious consequences [5].

Injectable anaesthetics are commonly used in ambulatory procedures, such as the treatment of wounds and $\mathrm{x}$-ray examinations, and they may also be used as preanaesthetic medication or for the induction of anaesthesia [4]. Ketamine is the most frequently used agent [6] and has been used in many different species of birds [7]. The combination of ketamine and benzodiazepines is also frequently used in bird species [8].

The majority of veterinary anaesthetists prefer inhalation anaesthesia, particularly isoflurane and sevoflurane, for avian species, although this method has a disadvantage in that it requires anaesthetic delivery equipment [2]. Among the different inhalant anaesthetics, sevoflurane has several advantages, such as a lower blood-gas partition coefficient and a non-pungent odour, and it also provides rapid induction and recovery $[9,10]$. Both sevoflurane and isoflurane have been proven safe for use in parrots $[11,12]$.

Within this context, the aim of this study was to evaluate the effectiveness of premedication in parrots (Amazona aestiva) using ketamine, either alone or in combination with diazepam, followed by the induction and maintenance of anaesthesia with sevoflurane. We hypothesised that premedication would facilitate handling and decrease sevoflurane requirements during anaesthesia.

\section{Methods \\ Birds}

Approval for the study was obtained from the local ethics committee and IBAMA (Brazilian Institute of the Environment and Renewable Natural Resources). The study utilised thirty-six Amazon parrots (Amazona aestiva) weighing 284 to $460 \mathrm{~g}(360 \pm 37 \mathrm{~g})$ that were housed at the Tietê Ecological Park (São Paulo, Brazil). Physical examinations were performed, and only birds with a good nutrition status and absence of respiratory disease were used. All procedures were performed within the park's facilities.

\section{Experimental procedure}

The birds were randomly distributed into three groups: the sevoflurane group (S) $(\mathrm{n}=12)$ was premedicated with $\mathrm{NaCl} 0.9 \%$ as a placebo, the ketamine/sevoflurane group (KS) $(\mathrm{n}=12)$ was premedicated with ketamine $10 \mathrm{mg} \cdot \mathrm{kg}^{-1}$, and the ketamine/diazepam/sevoflurane group (KDS) $(\mathrm{n}=12)$ was premedicated with ketamine $10 \mathrm{mg} . \mathrm{kg}^{-1}$ and diazepam (solubilised in propylene glycol) $0.5 \mathrm{mg} \cdot \mathrm{kg}^{-1}$ by intramuscular injection into the pectoral musculature. All drugs were diluted in $\mathrm{NaCl} 0.9 \%$, and the same volume $(0.2 \mathrm{ml})$ was administered for every group.

Determination of the minimum anaesthetic dose (MAD)

Fifteen minutes after premedication, anaesthetic induction was accomplished via the delivery of $4.5 \%$ sevoflurane in $100 \%$ oxygen with a flow rate of $1.5 \mathrm{~L} / \mathrm{min}$ through a facemask connected to a non-rebreathing circuit. The trachea was intubated with a non-cuffed endotracheal tube ( $2.5 \mathrm{~mm}$ internal diameter). After intubation, the end-tidal sevoflurane level was reduced to $3.5 \%$ and kept constant for 5 minutes. The partial pressure of expired $\mathrm{CO}_{2}$ $\left(\mathrm{P}_{\mathrm{E}} \mathrm{CO}_{2}\right)$ and the inspired and end-tidal sevoflurane concentration were monitored throughout the experiment with a multigas monitor (Poet IQ, Critcare, Waukesha, USA) connected to the breathing circuit through an 18-gauge needle inserted into the lumen of the endotracheal tube adapter. The sampling rate was measured at $150 \mathrm{ml} / \mathrm{min}$.

After the equilibration period, the bird was stimulated with a haemostat. The full length of the haemostat jaw was clamped to full ratchet lock to a claw for 1 minute or until gross purposeful movement was observed (such as lifting of the head and neck, flapping of the wing or kicking of the legs). When no movement was observed, the end-tidal sevoflurane concentration was reduced by $20 \%$. The stimulus was repeated after at least 5 minutes 
of equilibration. Additional decrements of the end-tidal sevoflurane concentration were made (20\% each time) until a purposeful movement occurred. After detecting movement, the end-tidal sevoflurane concentration was increased by $10 \%$; after 5 minutes of equilibration, the stimulus was repeated. The mean sevoflurane concentration between that allowing movement and that preventing movement was considered the minimum anaesthetic dose [13].

\section{Physiologic variable and arterial blood gas monitoring}

Heart rate (HR) was monitored using a stethoscope placed on the lower left lateral thoracic wall for 1 minute. Respiratory rate (RR), which was monitored by multigas monitor, was determined based on thoracic excursion for 1 minute after the induction of anaesthesia. Cloacal temperature (CT) was measured with a digital thermometer (digital clinical thermometer, Omrom, China). Systolic arterial blood pressure (SAP) was measured with a Doppler ultrasonic instrument (Ultrasonic Doppler 811 Parks Medical Electronics, Oregon, USA) with the sensor placed in the region of the tibial artery and a paediatric cuff $(2.2 \mathrm{~cm}$ width, approximately $40 \%$ of the bird thigh circumference) placed around the thigh.

Arterial blood $(0.3 \mathrm{ml})$ samples were collected anaerobically from the superficial ulnar artery into heparinised (sodium heparin) $1 \mathrm{ml}$ plastic syringes. The samples were analysed immediately using a portable analyser (i-STAT, Abbott, Illinois, USA) with cartridges measuring hydrogen potential $(\mathrm{pH})$, arterial carbon dioxide partial pressure $\left(\mathrm{PaCO}_{2}\right)$, arterial oxygen partial pressure $\left(\mathrm{PaO}_{2}\right)$, arterial oxygen saturation $\left(\mathrm{SaO}_{2}\right)$, base excess $(\mathrm{BE})$, bicarbonate ion $\left(\mathrm{HCO}_{3}^{-}\right)$, haematocrit $(\mathrm{Ht})$, haemoglobin $(\mathrm{Hb})$, sodium $\left(\mathrm{Na}^{+}\right)$, potassium $\left(\mathrm{K}^{+}\right)$, and ionised calcium (iCa) concentrations (EG7+, Abbott, Illinois, USA). Blood gas values were corrected based on the cloacal temperature. The i-STAT analyser was tested daily with quality tests with an external electronic simulator, as recommended by the manufacturer, prior to its use in experiments.

Each bird was positioned in a dorsal recumbent position, and its body temperature was maintained at approximately $40^{\circ} \mathrm{C}$ with a circulating warm water blanket (T/Pump, Gaymar, Orchard Park, NY, USA). Room temperature was maintained at $24-28^{\circ} \mathrm{C}$.

During the recovery from anaesthesia, the birds were wrapped in paper so that they could rise only when their muscular coordination was sufficient to allow them to maintain a bipedal position, thus avoiding spastic movements that could cause accidental injury.

All parameters described were evaluated every 5 minutes. For statistical analysis, these parameters were considered at the following time points: baseline, before premedi- cation (T0); 15 minutes after premedication (T1); and immediately after MAD determination (T2).

\section{Anaesthesia evaluation}

Induction time was defined as the time from the placement of the facemask to the time at which the animal succumbed in lateral recumbency, i.e., with relaxed wings and an absence of movement.

The extubation time was defined as the time from the termination of sevoflurane administration until tracheal extubation, which occurred immediately following the recovery of increased jaw tone.

The time required to return to a bipedal position was determined as the interval from the termination of sevoflurane administration until the bird returned to an upright position.

The time to complete recovery was defined as the time between the termination of sevoflurane administration until the moment the bird returned to a bipedal position, walked in the cage, and was able to remain stable on a perch.

The degree of sedation, induction, muscle relaxation, and recovery from anaesthesia were evaluated subjectively. A score from 0 to 2 was given for each category, with a higher number indicating an improved quality of the variable (Table 1).

\section{Statistical analysis}

The primary outcome was a decreased MAD in the premedicated groups. The sample number (12 per group) was calculated based on the published chicken sevoflurane MAD $2.2 \pm 0.32 \%$ [10], a reduction of $20 \%$ in premedicated groups, and a power of $80 \%$.

The data were tested for normality using the KolmogorovSmirnov test. Parametric data (cardiorespiratory and blood gas) were compared within groups and between groups by a two-way repeated measures analysis of variance (ANOVA) with the Tukey-Kramer post hoc multiple comparison test. The MAD, time for induction, and recovery were compared between groups by one-way ANOVA and the Tukey-Kramer post-hoc multiple comparison test. Non-normally distributed data (sedation, induction, muscle relaxation, and recovery scores) were compared between groups using the Kruskal-Wallis test. When appropriate, a post-hoc multiple comparison analysis was performed using Dunn's test (SigmaStat 3.11, Systat Software Inc., San Jose, CA, USA). A P $<0.05$ was considered statistically significant. The data are reported as the mean \pm standard deviation unless otherwise indicated.

\section{Results}

The MAD in the group $S(2.4 \pm 0.37 \%)$ was significantly higher than that in the KS $(1.7 \pm 0.39 \%, \mathrm{P}<0.001)$ and 
Table 1 Evaluation of the quality of sedation, induction, muscle relaxation, and recovery from anaesthesia in parrots anaesthetised with sevoflurane

\begin{tabular}{lll}
\hline Criteria & Score & Observation \\
\hline Sedation & 2 & $\begin{array}{l}\text { Animal is undisturbed after sedation, allows manipulation without stress and accepts the mask for the induction of } \\
\text { anaesthesia. }\end{array}$ \\
& 1 & $\begin{array}{l}\text { Animal resistant to manipulation, appears stressed and avoids the mask. } \\
\text { Induction }\end{array}$ \\
& 2 & Animal does not accept manipulation or mask. \\
& 1 & $\begin{array}{l}\text { Tracheal intubation is performed easily; animal is relaxed, and does not exhibit reflexes in response to intubation stimulus; } \\
\text { absence of excitation. }\end{array}$ \\
& 0 & Not possible to proceed with tracheal intubation; wing and leg movements and vocalisation observed. \\
Muscle & 2 & Complete muscle relaxation. \\
relaxation & 1 & Light muscle tonus. \\
& 0 & Intensive muscle tonus of wings and contracted pelvic members. \\
Recovery & 2 & Calm animal, without excitation or vocalisation. \\
& 1 & Smooth awakening, but animal tries to remain standing up, beating the wings. \\
& 0 & Disturbed awakening, with violent beating of wings violently and vocalization.
\end{tabular}

KDS $(1.3 \pm 0.32 \%, \mathrm{P}<0.001)$ groups. The values for the group KDS were significantly lower than those for the group KS $(\mathrm{P}=0.001)$.

Sedation was observed in both premedicated groups KS and KDS. There was no difference in the quality of sedation produced by ketamine alone or associated with diazepam. The birds in the group KS showed less muscle relaxation compared with the birds in the $\mathrm{S}$ and KDS groups. The scores reflecting the degree of sedation, induction, muscle relaxation, and recovery from anaesthesia are shown in Figure 1.

The anaesthetic induction time was significantly shorter in the two premedicated groups (Table 2). The extubation times varied among the groups and were significantly shorter in the group $\mathrm{KS}$ (premedicated with ketamine alone). The time required to return to an
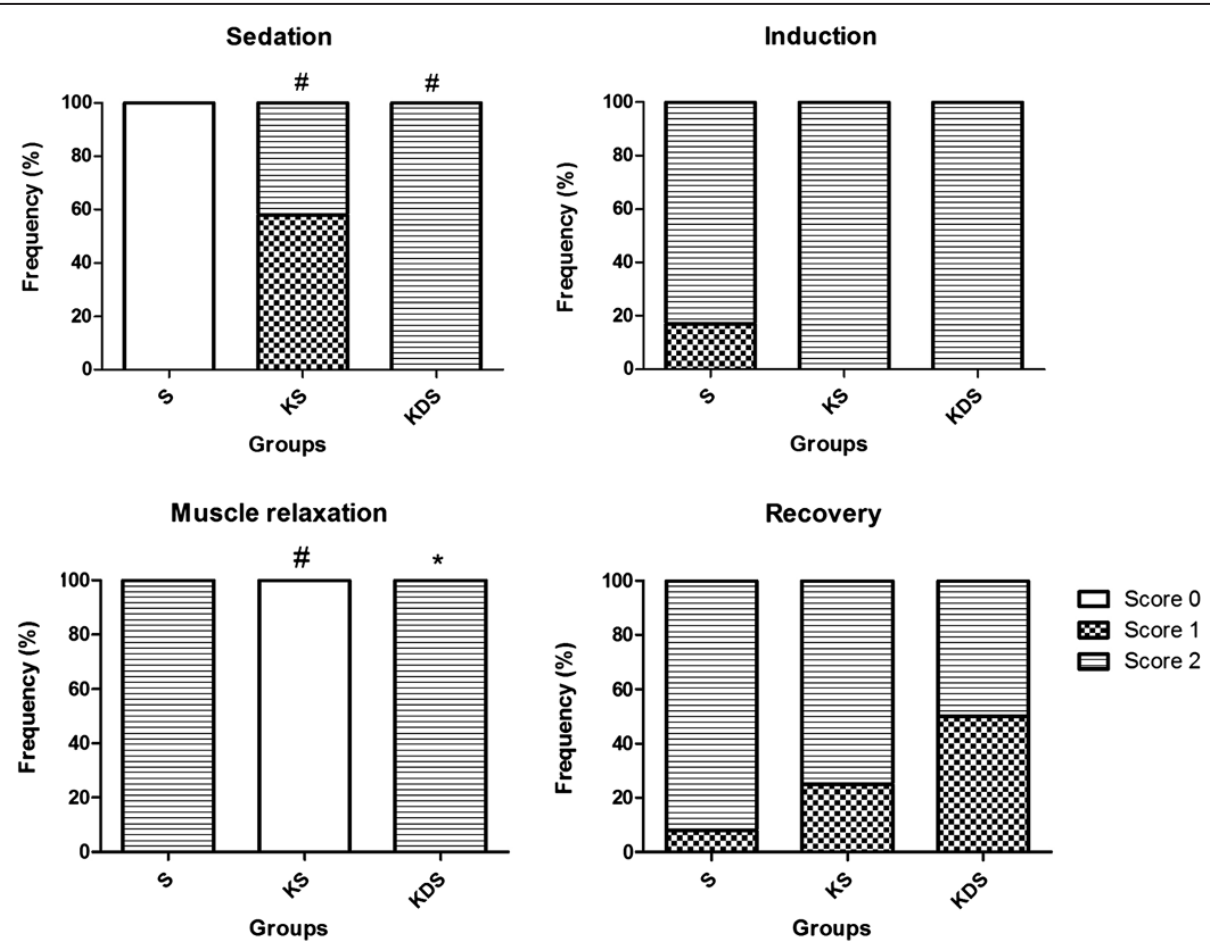

Figure 1 Anaesthesia quality scores. \# $P<0.05$ compared with the $S$ group; ${ }^{*} P<0.05$ compared with the KS group. 
Table 2 Times for variables associated with anaesthesia (mean \pm SD)

\begin{tabular}{ccccc}
\hline Group & \multicolumn{4}{c}{ Time (s) } \\
\cline { 2 - 5 } & Induction & Extubation & Upright & Recovery \\
\hline S & $82 \pm 29.7$ & $56 \pm 23.8$ & $129 \pm 63.8$ & $348 \pm 92.4$ \\
KS & $46 \pm 13.7^{\#}$ & $48 \pm 21.1$ & $239 \pm 120.6^{\#}$ & $575 \pm 192.3$ \\
KDS & $38 \pm 12.7^{\#}$ & $97 \pm 38.5^{\#^{*}}$ & $258 \pm 97.5^{\#}$ & $909 \pm 331.5^{\#^{*}}$ \\
\hline
\end{tabular}

\# $\mathrm{P}<0.05$ compared with $\mathrm{S}$; ${ }^{*} \mathrm{P}<0.05$ compared with $\mathrm{KS}$.

upright position was significantly longer in the premedicated groups. The total anaesthesia times (from T0 to T2) were $52.6 \pm 14.6,67.2 \pm 15.0$, and $78.9 \pm 11.2$ for groups S, KS, and KDS, respectively. This time was significantly shorter in the group $\mathrm{S}$ than in the KS and KDS groups $(\mathrm{P}=0.036$ and $\mathrm{P}<0.001$, respectively).

The RR decreased significantly at T1 in the KS and KDS groups and at T2 in all groups (Table 3). SAP in the group $\mathrm{S}$ was significantly lower at $\mathrm{T} 2$ than at $\mathrm{T} 0$ and T1. At T2, the SAP in the group S was also significantly lower than that in the KS and KDS groups. The CT in the group $\mathrm{S}$ decreased at T2, while in the KS and KDS groups, the CT was significantly lower at T1 and T2.

The $\mathrm{pH}$ decreased significantly at T2 compared with T0 in the group KDS, while the values of $\mathrm{PaCO}_{2}, \mathrm{PaO}_{2}$, $\mathrm{SaO}_{2}, \mathrm{BE}$, and $\mathrm{HCO}_{3}^{-}$increased significantly at $\mathrm{T} 2$ in the three groups compared with T0 (Table 4).

After the determination of the MAD, we observed a $\mathrm{P}_{\mathrm{E}} \mathrm{CO}_{2}$ of $43.4 \pm 4.77 \mathrm{mmHg}$ in the group $\mathrm{S}, 40.4 \pm$ $3.78 \mathrm{mmHg}$ in the group $\mathrm{KS}$, and $45.2 \pm 0.84 \mathrm{mmHg}$ in the group KDS. The $\mathrm{PaCO}_{2}$, analysed at the same time, was $39.7 \pm 5.33 \mathrm{mmHg}$ in the group $\mathrm{S}, 34.1 \pm 6.04 \mathrm{mmHg}$ in the group $\mathrm{KS}$, and $40.1 \pm 7.77 \mathrm{mmHg}$ in the group KDS.

Table 3 Physiological parameters (mean \pm SD)

\begin{tabular}{ccccc}
\hline Parameter & Group & T0 & T1 & T2 \\
\hline HR (beat.min $\left.{ }^{-1}\right)$ & S & $183 \pm 33$ & $164 \pm 23$ & $195 \pm 34^{\dagger}$ \\
& KS & $180 \pm 38$ & $167 \pm 33$ & $193 \pm 54$ \\
& KDS & $174 \pm 33$ & $163 \pm 24$ & $180 \pm 32$ \\
RR (breaths.min $\left.{ }^{-1}\right)$ & S & $93 \pm 26$ & $79 \pm 31$ & $31 \pm 06^{\Delta \dagger}$ \\
& KS & $65 \pm 31^{\#}$ & $29 \pm 08^{\# \Delta}$ & $22 \pm 06^{\Delta}$ \\
SAP $(\mathrm{mmHg})$ & KDS & $71 \pm 28^{\#}$ & $31 \pm 09^{\# \Delta}$ & $21 \pm 07^{\Delta}$ \\
& $\mathrm{S}$ & $170 \pm 29$ & $176 \pm 26$ & $136 \pm 21^{\Delta \dagger}$ \\
& KS & $175 \pm 19$ & $177 \pm 22$ & $163 \pm 31^{\#}$ \\
CT ( $\left.{ }^{\circ} \mathrm{C}\right)$ & KDS & $175 \pm 24$ & $175 \pm 37$ & $168 \pm 25^{\#}$ \\
& $\mathrm{~S}$ & $42 \pm 0.52$ & $41.5 \pm 0.86$ & $40 \pm 1.28^{\Delta \dagger}$ \\
& KS & $41.8 \pm 0.69$ & $41 \pm 0.5^{\Delta}$ & $40.4 \pm 0.94^{\Delta}$ \\
& KDS & $41.7 \pm 0.71$ & $40.2 \pm 0.57^{\Delta \#}$ & $40.3 \pm 0.84^{\Delta}$
\end{tabular}

$H R$ heart rate, $R R$ respiratory rate, SAP systolic blood arterial pressure, $C T$ cloacal temperature; T0: before premedication; T1: 15 min after premedication; T2: after MAD; \# $\mathrm{P}<0.05$ compared with $\mathrm{S} ; \Delta \mathrm{P}<0.05$ compared with T0; $+\mathrm{P}<0.05$ compared with $\mathrm{T} 1$.
Table 4 Arterial blood gases and electrolytes (mean \pm SD)

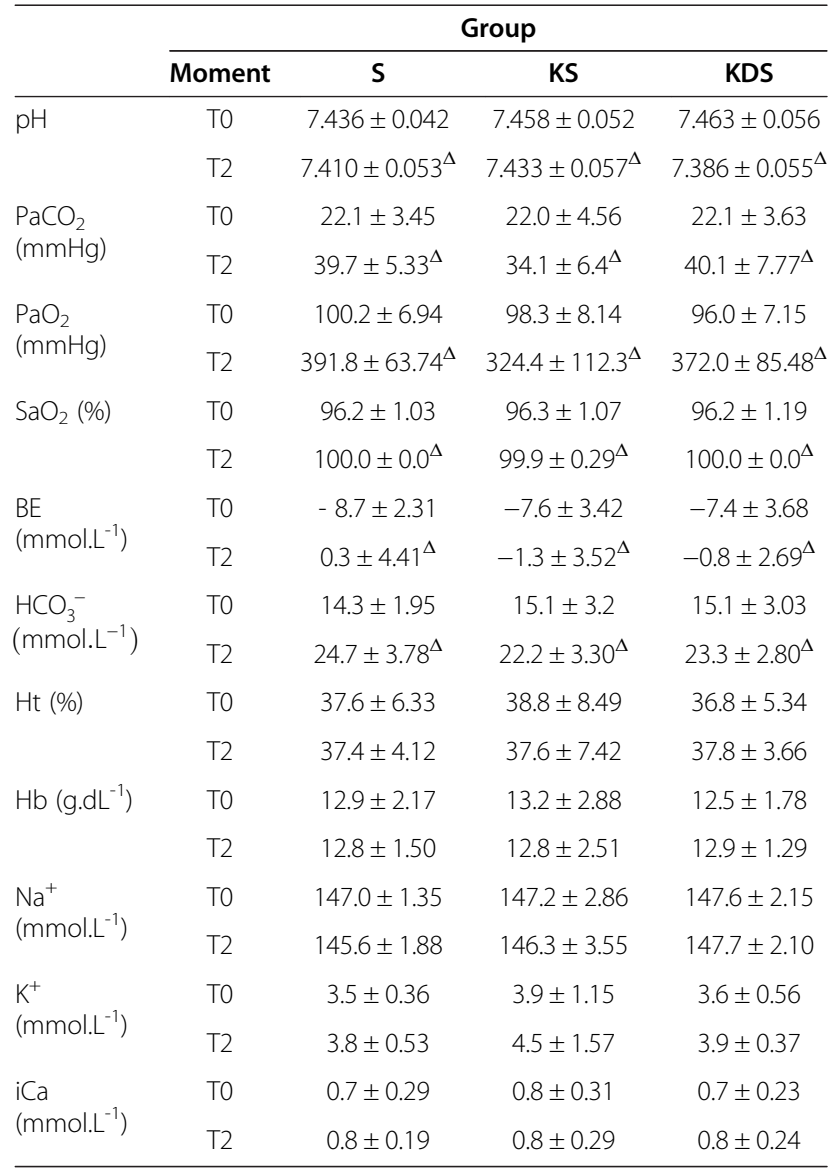

$\mathrm{PaCO}_{2}$ arterial carbon dioxide partial pressure, $\mathrm{PaO}_{2}$ arterial oxygen partial pressure, $\mathrm{SaO}_{2}$ arterial oxygen saturation, $\mathrm{BE}$ base excess, $\mathrm{HCO}_{3}$ bicarbonate ion concentration, $\mathrm{Ht}$ haematocrit, $\mathrm{Hb}$ haemoglobin concentration, $\mathrm{Na}^{+}$serum sodium concentration, $K^{+}$serum potassium concentration, $i C a$ serum ionised calcium concentration, $T 0$ before premedication, $T 2$ after MAD; $\Delta \mathrm{P}<0.05$ compared with TO.

\section{Discussion}

The use of ketamine, ketamine-diazepam, and sevoflurane proved to be adequate for clinical restraint and anaesthesia in parrots. In the present study, premedication of parrots with ketamine alone or in combination with diazepam promoted sedation, decreased struggling during induction, and also reduced the MAD.

In mammals, minimum alveolar concentration (MAC) has been used as the index of potency for inhalant anaesthetics [14]. In birds, although this term is inappropriate for this species because they do not possess alveolus lung cavities, the potency of these inhalants has been determined by methods similar to those used in mammals. Parameters such as Minimum Anaesthetic Concentration [10], Effective Dose $\left(\mathrm{ED}_{50}\right)$ [15], and Minimum Anaesthetic Dose [13] have been used to express the potency of inhalant anaesthetics in birds.

In the present study, the MAD obtained with the use of sevoflurane was $2.3 \pm 0.31 \%$, which is lower than the value 
observed in a previous study of parrots [16]. However, it is similar to the value of $2.35 \%$ obtained in thick-billed parrots [12] and the values obtained in other species, such as $2.21 \%$ in chickens [10], $2.36 \pm 0.46 \%$ in dogs [17], $2.8 \%$ in cats [18], and $2.3 \%$ in horses [19].

Several factors may alter the MAC of inhalant anaesthetics in mammals, including animal age, temperature extremes, circadian rhythms, hypoxemia, hypotension, and the presence of other chemical elements such as sedatives, narcotics, and tranquilisers [14]. In this study, the MAD of sevoflurane diminished significantly when the parrots were pre-medicated either with ketamine or a combination of ketamine/diazepam (decreased by $25 \%$ and $45.8 \%$, respectively).

Although there were no differences between the groups KS and KDS, the quality of sedation was higher in the premedicated groups. Indeed, the parrots that had not been premedicated were difficult to handle because they refused to accept manual restraint and fought against the placing of the induction mask, thus making the performance of the medical procedure dangerous for both the anaesthetist and the animal. In contrast, the birds that were premedicated were easy to handle, and the placement of the induction mask was permitted without any indication of stress. Thus, one of the main findings of this study is that premedication improved the quality of sedation and reduced the stress to the birds.

The quality of intubation did not vary among the groups, and no difference in the ease of introducing the endotracheal tube was noted. In all birds, the induction was considered to be free of any type of excitation after the mask had been placed. The use of ketamine and ketamine/diazepam decreased the induction time (44\% and 54\% in KS and KDS groups, respectively), presumably because these agents potentiate inhalant anaesthetics [20]. The induction time observed in the birds that did not receive premedication was shorter than those reported for thick-billed parrots (3 min with 5\% sevoflurane in oxygen $1 \mathrm{~L} / \mathrm{min}$ ) [12] and red-tailed hawks (3.6 minutes with $5.75 \%$ sevoflurane in oxygen $1 \mathrm{~L} / \mathrm{min}$ ) [21]. However, comparing the times necessary for induction across these studies is difficult due to differences in species and the definition of time to induction. The oxygen flow and the anaesthetic inspiratory concentration may also influence the induction time [9].

In our analysis, the extubation and recovery times were both significantly different among the groups. The use of benzodiazepines can increase recovery time because these molecules increase muscle relaxation, have sedative and hypnotic properties, and also potentiate dissociative anaesthetics. Diazepam is frequently used because it produces similar muscle relaxation but has a longer duration of sedation than midazolam [22,23]. Midazolam may be a better choice due to its water solubility, but previous experience has shown no clinical muscle damage due to the injection of a small volume of propylene glycol diazepam.

In the present study, the quality of recovery was similar in the three groups analysed; however, we observed that the recovery process was more gradual in the premedicated groups. Very rapid recovery has been observed in birds that were anaesthetised with inhalants only [24]. Although the time required to return to a bipedal position differed significantly among groups, from a clinical point of view, they were very similar, ranging from $2.15 \mathrm{~min}$ in the group $\mathrm{S}$ to $4.3 \mathrm{~min}$ in the group KDS. Wrapping the birds in paper contributed to the uneventful recovery. The time necessary for complete recovery in the group sevoflurane was similar to those reported in a different study in the same species (4.47 $\mathrm{min})$ [16] and in roosters $(5.5 \mathrm{~min})$ [25]. In the premedicated birds, the recovery times were $9.6 \pm 3.2 \mathrm{mi}$ nutes (ketamine group) and $15.2 \pm 8.9$ minutes (ketamine/diazepam group). Premedication with ketamine alone or in association with diazepam increased the length of MAD determination, requiring more end-tidal sevoflurane concentration decrements and equilibrium times, thus resulting in longer times from T0 to T2. This longer anaesthesia time is unlikely to have affected the length of recovery from sevoflurane, which has a low blood/gas partition coefficient (0.69) [26], but the possibility of such interference cannot be ruled out.

When comparing time T0 to T1, we observe that the use of premedication significantly decreased the respiratory rate, which may be explained by the tranquilising and sedative effects of the agent used. In dogs, ketamine causes a transient lowering of the respiratory rate, minute volume, and $\mathrm{PaO}_{2}$, with an initial increase in $\mathrm{PaCO}_{2}$ [27]. No depression of the respiratory rate was observed in domestic chickens injected with a combination of $20 \mathrm{mg} \cdot \mathrm{kg}^{-1}$ of ketamine and $2 \mathrm{mg} . \mathrm{kg}^{-1}$ of diazepam [28]. Ketamine causes fewer cardiovascular and respiratory effects than other anaesthetics [29]. In our study, the basal respiratory rates of the birds in all three groups studied were elevated, most likely reflecting the hyperventilation caused by stress during restraint. This could be considered a limitation of the study itself, given that the study involves non-domesticated animals. Because these birds are easily stressed and difficult to handle, the use of pre-anaesthetic medication is even more justifiable. A decrease in respiratory rate was observed in all of the groups analysed after determining the MAD (T2) in comparison with baseline (T0), and there were no significant differences among the groups, suggesting that premedication does not significantly potentiate this decrease. The respiratory rates measured after the application of the anaesthetic (T2) were similar to those observed in another study in the same species [16] and in 
thick-billed parrots [12] and higher than the values observed in chickens [30].

The HR and SBP were similar in all three groups at T1. However, in group $\mathrm{S}$, the heart rate increased significantly during sevoflurane administration. This increase is likely a result of a significant decrease in blood pressure related to the higher concentration of inhaled anaesthetic verified in this group at this time point. Similar results were observed in chickens anaesthetised with sevoflurane, in which the HR increased and the SBP decreased with increasing inhaled concentrations [30].

Although a circulating-water warming blanket was utilised, it was not sufficient to prevent a temperature decrease in all groups at T2. The circulating-water blanket minimises heat loss but not as efficiently as the forced-air warmer system [31]. In the KS and KDS groups, the decrease in CT was observed immediately following premedication, but at T2, the CT was similar in all groups, showing that premedication did not enhance heat loss over time. The longer anaesthesia time observed in the KDS group also did not increase heat loss. Temperature may alter anaesthetic requirements [14], but it is unlikely that the differences observed at T1 contributed to the decreased MAD in the KDS and KS groups.

The analyses of the blood gas and electrolytes in nonanaesthetised parrots are similar to the data obtained under similar conditions in other studies involving avian species [8,32-35]. Even with the appropriate physical restraint of the birds, the stress of this procedure causes hyperventilation, which produces a decrease in $\mathrm{PaCO}_{2}$.

Inhalant anaesthetics cause respiratory depression, depending on the dose, as reported by a large number of authors and evidenced by an increase in $\mathrm{PaCO}_{2}$ [34]. Hypercapnia has been shown to induce arrhythmia in ducks anaesthetised with halothane [36]. These effects may be due to the myocardium-sensitising effect of halothane and the sympathomimetic effect of $\mathrm{CO}_{2}$. Sevoflurane is likely less apt to induce arrhythmias because it does not sensitise the myocardium to catecholamines [37]. In our study, the $\mathrm{PaCO}_{2}$ at the moment in which the MAD was determined was significantly increased compared with the baseline value in all groups but was compatible with the results obtained in chickens $(46 \mathrm{mmHg}$ with $2.2 \%$ sevoflurane) [30] and thick-billed parrots (38.6 $\mathrm{mmHg}$ with $2.35 \%$ sevoflurane) [12]. Moreover, the $\mathrm{PaCO}_{2}$ values in this study were lower than those reported in ducks $(57.2 \pm 4.2$ and $93.9 \pm 11.8 \mathrm{mmHg}$ using 1.0 and 1.5 MAD isoflurane, respectively) [34] and parrots (55.87 $\mathrm{mmHg}$ with $3.44 \%$ sevoflurane) [16].

It must be noted that the significant increase in $\mathrm{PaCO}_{2}$ observed following the administration of sevoflurane was due, in part, to the fact that the parrots suffered from respiratory alkalosis at $\mathrm{T} 0$ as a result of the hyperventilation caused by restraint-related stress. Thus, the difference in the concentrations at $\mathrm{T} 0$ and $\mathrm{T} 2$ may seem to be much greater than it really is. In contrast, it is virtually impossible to collect blood samples from these birds in a stressfree situation because they are not domesticated, which undoubtedly limits our ability to accurately evaluate baseline $\mathrm{PaCO}_{2}$ values.

In this study, the $\mathrm{P}_{\mathrm{E}} \mathrm{CO}_{2}$ values exceed the $\mathrm{PaCO}_{2}$ values by approximately $5 \mathrm{mmHg}$, similar to the results observed in grey parrots anaesthetised with isoflurane [38]. In mammals, the exact opposite occurs; the $\mathrm{P}_{\mathrm{E}} \mathrm{CO}_{2}$ is lower than the $\mathrm{PaCO}_{2}[39,40]$. This result is explained by the fact that in mammals, the airflow in the alveolus is bidirectional and the physiological dead space has an important effect on the $\mathrm{P}_{\mathrm{E}} \mathrm{CO}_{2}$, whereas in birds, parabronchial air flow is unidirectional throughout the respiratory cycle [3]. The cross-current gas exchange in parabronchi also contributes to a higher gas exchange efficiency than in mammals [41]. Considering the anatomical and physiological differences between birds and mammals, capnography is a reliable and important tool for monitoring the $\mathrm{PaCO}_{2}$ and the degree of respiratory depression during anaesthesia in parrots.

The small size of the birds $(360 \pm 37 \mathrm{~g})$ can lead to the assumption of inaccuracy in capnographic measurements. However, the sampling rate $(150 \mathrm{ml} / \mathrm{min})$ did not exceed the minute ventilation calculated at approximately $160-230 \mathrm{ml}$ $\left(\mathrm{RR} \times\left(22.9 \times\right.\right.$ weight $\left.\left.^{1.08}\right)\right)$ [42]. The fresh gas flow was also 10 times the sampling rate. Moreover, the capnogram inspiratory $\mathrm{CO}_{2}$ was always near zero, indicating no reinhalation in the system. Upon the increase in sevoflurane delivery, the obtained inspiratory sevoflurane was higher than the expiratory concentration, reaching values close to equilibrium after the stabilisation period. Still, the possibility of some degree of inaccuracy in the $\mathrm{P}_{\mathrm{E}} \mathrm{CO}_{2}$ measurements should be recognised as a limitation of this study.

\section{Conclusions}

Ketamine, delivered alone or in combination with diazepam, considerably decreased the MAD of sevoflurane in parrots (Amazona aestiva). Ketamine alone or in combination with diazepam promoted a good quality of sedation, thereby improving handling and reducing the stress of the birds. All protocols provided safe anaesthesia in this avian species.

\section{Abbreviations}

BE: Base excess in mmol.L $\mathrm{L}^{-1} ; \mathrm{CT}$ : Cloacal temperature in ${ }^{\circ} \mathrm{C}$; group $\mathrm{KDS}$ : group ketamine/diazepam/sevoflurane; group KS: group ketamine/sevoflurane; group $\mathrm{S}$ : group sevoflurane; $\mathrm{Hb}$ : concentration of haemoglobin in g.dL ${ }^{-1} ; \mathrm{HCO}_{3}^{-}$: concentration of bicarbonate ions in $\mathrm{mmol.L}^{-1} ; \mathrm{HR}$ : Heart rate; Ht: Haematocrit in \%; IBAMA: Brazilian Institute for the Preservation of the Environment and Renewable Natural Resources; iCa: Serum concentration of calcium in mmol.L-1; $\mathrm{K}^{+}$: Serum concentration of potassium in $\mathrm{mmol}^{-L^{-1}}$; MAC: Minimum alveolar concentration; MAD: Minimum anaesthetic dose; $\mathrm{Na}^{+}$: Serum concentration of sodium in $\mathrm{mmol}^{-1} \mathrm{~L}^{-1} \mathrm{PaCO}_{2}$ : Partial arterial carbon dioxide pressure in $\mathrm{mmHg}$; $\mathrm{PaO}_{2}$ : Partial arterial oxygen pressure in $\mathrm{mmHg}$; RR: Respiratory rate; $\mathrm{SaO}_{2}$ : Arterial oxygen saturation in \%; SBP: Systolic blood pressure in $\mathrm{mmHg}$; TO: Time before premedication; T1: 15 minutes after premedication; T2: After MAD determination. 


\section{Competing interests}

The authors declare that they have no competing interests.

\section{Authors' contributions}

JOCAJ and DTF designed the study, evaluated the data, and obtained the funding for the study. WP and DAO conducted the experiments, collected all samples, performed the blood gas analysis, and helped to write the manuscript. TLN and AMA helped with the editing and revision of the manuscript. All authors read and approved the final manuscript.

\section{Acknowledgements}

This study was supported by grants from CNPq. These data were presented in part at the AVA European College of Veterinary Anaesthesia 2008 Conference in Paris, France.

\section{Author details}

${ }^{1}$ Department of Animal Science, Universidade Federal Rural do Semi-Árido, Av. Francisco Mota, 572, Bairro Costa e Silva, CEP: 59.625-900, Mossoró, RN, Brazil. 'Laboratory of Medical Investigation/Anesthesiology (LIM/08), Faculdade de Medicina da Universidade de São Paulo, Av. Dr. Arnaldo, 455, Cerqueira César, CEP 01246903, São Paulo, SP, Brazil. ${ }^{3}$ Department of Surgery, Faculdade de Medicina Veterinária e Zootecnia da Universidade de São Paulo, Av. Prof. Dr. Orlando Marques de Paiva, 87 CEP 05508 270, Cidade Universitária, São Paulo, SP, Brazil.

Received: 5 February 2013 Accepted: 12 July 2013

Published: 17 July 2013

\section{References}

1. Hall LW, Clarke KW, Trim CM: Anaesthesia of birds, laboratory animals and wild animals. In Veterinary Anaesthesia. Edited by Hall LW, Clarke KW, Trim CM. WB Saunders Co; 2001:463-479.

2. Gunkel C, Lafortune M: Current techniques in avian anesthesia. Seminars in Avian and Exotic Pet Medicine 2005, 14:263-276.

3. Hawkings MG, Pascoe PJ: Cagebirds. In Zoo Animal \&Wildlife Imobilization and Anesteshia. 1st edition. Edited by West G, Heard D, Caulkitt N. Blackwell publishing; 2007.

4. Skarda RT, Berdnarski RM: Anesthetic procedures in exotics pets. In Handbook of veterinary anesthesia. 2nd edition. Edited by Muir WW. Hubbel JAE. St. Louis: Mosby; 1995:341-371.

5. Gandall PC: Surgical techniques and anesthesia. In Diseases of cage and aviary birds. Edited by ML P. Philadelphia: Lea \& Febiger; 1969:217-231.

6. Christensen J, Fosse RT, Halvorsen OJ, Morild I: Comparison of various anesthetic regimens in the domestic fowl. Am J Vet Res 1987, 48:1649-1657.

7. McGrath CJ, Lee JC, Campbell VL: Dose-response anesthetic effects of ketamine in the chicken. Am J Vet Res 1984, 45:531-534.

8. Paula W, Fantoni DT, Otsuki DA, Oliveira MF, Barreto Junior RA: Avaliação da associação cetamina/diazepam/propofol na anestesia de emas (Rhea americana americana). Braz J Vet Res Anim Sci 2004, 4:4-5.

9. Eger El 2nd: Inhaled Anesthetics: uptake and distribution. In Miller's Anesthesia. 7th edition. Edited by Miller RD. Philadelphia: Elsevier; 2010.

10. Naganobu K, Fujisawa Y, Ohde H, Matsuda Y, Sonoda T, Ogawa H: Determination of the minimum anesthetic concentration and cardiovascular dose response for sevoflurane in chickens during controlled ventilation. Vet Surg 2000, 29:102-105.

11. Mercado JA, Larsen RS, Wack RF, Pypendop BH: Minimum anesthetic concentration of isoflurane in captive thick-billed parrots (Rhynchopsitta pachyrhyncha). Am J Vet Res 2008, 69:189-194.

12. Phair KA, Larsen RS, Wack RF, Shilo-Benjamini Y, Pypendop BH: Determination of the minimum anesthetic concentration of sevoflurane in thick-billed parrots (Rhynchopsitta pachyrhyncha). Am J Vet Res 2012, 73:1350-1355.

13. Ludders JW, Mitchell GS, Schaefer SL: Minimum anesthetic dose and cardiopulmonary dose response for halothane in chickens. Am J Vet Res 1988, 49:929-932.

14. Quasha AL, Eger El 2nd, Tinker JH: Determination and applications of MAC. Anesthesiology 1980, 53:315-334.

15. Curro TG, Brunson DB, Paul-Murphy J: Determination of the ED50 of isoflurane and evaluation of the isoflurane-sparing effect of butorphanol in cockatoos (Cacatua spp.). Vet Surg 1994, 23:429-433.
16. Nicolau AA, Fantoni DT, Auler Junior JOC, Ambrosio A: O sevoflurano em psitacídeos (Amazonas aestiva): Determinação da dose mínima (DAM) para produção de anestesia geral. Ciencia Rural 2002, 32:781-786.

17. Kazama T, Ikeda K: The comparative cardiovascular effects of sevoflurane with halothane and isoflurane. J Anesth 1988, 2:63-68.

18. Hikasa Y, Ohe N, Takase K, Ogasawara S: Cardiopulmonary effects of sevoflurane in cats: comparison with isoflurane, halothane, and enflurane. Res Vet Sci 1997, 63:205-210.

19. Aida H, Mizuno Y, Hobo S, Yoshida K, Fujinaga T: Determination of the minimum alveolar concentration (MAC) and physical response to sevoflurane inhalation in horses. J Vet Med Sci 1994, 56:1161-1165.

20. Reves JG, Glass PSA, Lubrasky DA, McEvoy MD: Intravenous nonopiod anesthetics. In Miller's Anesthesia. Edited by Miller RD. Philadelphia: Elsevier; 2005:315-378.

21. Granone TD, de Francisco ON, Killos MB, Quandt JE, Mandsager RE, Graham LF: Comparison of three different inhalant anesthetic agents (isoflurane, sevoflurane, desflurane) in red-tailed hawks (Buteo jamaicensis). Vet Anaesth Analg 2012, 39:29-37.

22. Vesal N, Zare P: Clinical evaluation of intranasal benzodiazepines, alpha-agonists and their antagonists in canaries. Vet Anaesth Analg 2006 33:143-148.

23. Bigham AS, Zamani Moghaddam AK: Finch (Taeneopygia guttata) sedation with intranasal administration of diazepam, midazolam or xylazine. J Vet Pharmacol Ther 2013, 36:102-104.

24. Concannon KT, Dodam JR, Hellyer PW: Influence of a mu- and kappaopioid agonist on isoflurane minimal anesthetic concentration in chickens. Am J Vet Res 1995, 56:806-811.

25. Guimarães LD, Moraes AN, Campello RAV, Oleskovicz N, Ulliana D: Estudo comparativo entre sevoflurano, halotano e isoflurano em Gallus domesticus. Ciencia Rural 2000, 30:999-10004.

26. Eger El 2nd, Johnson BH: Rates of awakening from anesthesia with I-653, halothane, isoflurane, and sevoflurane: a test of the effect of anesthetic concentration and duration in rats. Anesth Analg 1987, 66:977-982.

27. Haskins SC, Farver TB, Patz JD: Cardiovascular changes in dogs given diazepam and diazepam-ketamine. Am J Vet Res 1986, 47:795-798.

28. Varner J, Clifton KR, Poulos S, Broderson JR, Wyatt RD: Lack of efficacy of injectable ketamine with xylazine or diazepam for anesthesia in chickens. Lab Anim (NY) 2004, 33:36-39.

29. Wright M: Pharmacologic effects of ketamine and its use in veterinary medicine. J Am Vet Med Assoc 1982, 180:1462-1471.

30. Naganobu K, Ise K, Miyamoto T, Hagio M: Sevoflurane anaesthesia in chickens during spontaneous and controlled ventilation. Vet Rec 2003, 152:45-48.

31. Rembert MS, Smith JA, Hosgood G, Marks SL, Tully TN: Comparison of traditional thermal support devices with the forced-air warmer system in anesthetized Hispaniolan Amazon parrots (Amazona ventralis). J Avian Med Surg 2001, 15:187-193.

32. Paula W, Fantoni DT, Otsuki DA, Auler JOC: Blood-gas and electrolyte values for Amazon parrots (Amazona aestiva). Pesquisa Veterinaria Brasileira 2008, 28:108-112.

33. Calder WA Jr, Schmidt-Nielsen K: Evaporative cooling and respiratory alkalosis in the pigeon. Proc Natl Acad Sci USA 1966, 55:750-756.

34. Ludders JW, Mitchell GS, Rode J: Minimal anesthetic concentration and cardiopulmonary dose response of isoflurane in ducks. Vet Surg 1990, 19:304-307.

35. Schmitt PM, Powell FL, Hopkins SR: Ventilation-perfusion inequality during normoxic and hypoxic exercise in the emu. J App/ Physiol 2002, 93:1980-1986.

36. Naganobu K, Hagio M, Sonoda T, Kagawa K, Mammoto T: Arrhythmogenic effect of hypercapnia in ducks anesthetized with halothane. Am J Vet Res 2001, 62:127-129.

37. Imamura S, Ikeda K: Comparison of the epinephrine-induced arrhythmogenic effect of sevoflurane with isoflurane and halothane. J Anesth 1987, 1:62-68.

38. Edling TM, Degernes LA, Flammer K, Horne WA: Capnographic monitoring of anesthetized African grey parrots receiving intermittent positive pressure ventilation. J Am Vet Med Assoc 2001, 219:1714-1718.

39. Grosenbaugh DA, Muir WW 3rd: Accuracy of noninvasive oxyhemoglobin saturation, end-tidal carbon dioxide concentration, and blood pressure monitoring during experimentally induced hypoxemia, hypotension, or hypertension in anesthetized dogs. Am J Vet Res 1998, 59:205-212. 
40. Teixeira Neto FJ, Carregaro AB, Mannarino R, Cruz ML, Luna SP: Comparison of a sidestream capnograph and a mainstream capnograph in mechanically ventilated dogs. J Am Vet Med Assoc 2002, 221:1582-1585.

41. Powell FL, Hopkins SR: Comparative physiology of lung complexity: implications for gas exchange. News Physiol Sci 2004, 19:55-60.

42. Frappell PB, Hinds DS, Boggs DF: Scaling of respiratory variables and the breathing pattern in birds: an allometric and phylogenetic approach. Physiol Biochem Zool 2001, 74:75-89.

doi:10.1186/1746-6148-9-142

Cite this article as: Paula et al:: The effect of premedication with

ketamine, alone or with diazepam, on anaesthesia with sevoflurane in parrots (Amazona aestiva). BMC Veterinary Research 2013 9:142.

\section{Submit your next manuscript to BioMed Central and take full advantage of:}

- Convenient online submission

- Thorough peer review

- No space constraints or color figure charges

- Immediate publication on acceptance

- Inclusion in PubMed, CAS, Scopus and Google Scholar

- Research which is freely available for redistribution 